\title{
Teachers' evaluation of formative assessment on summative assessment in undergraduate medical education
}

\author{
Prof. Sakhawat Hossain ${ }^{\prime}$, Dr. Nazma Begum ${ }^{2}$, Prof. Dr. Md. Humayun Kabir Talukder ${ }^{3}$
}

\begin{abstract}
Background: Assessment is important in all forms of learning. Formative assessments have evolved as a means to adapt to student needs. Summative assessment designed to make judgments about students' performance and produce grades Formative assessment is the assessment that takes place during a course or programming of study whereas summative assessment is normally carried out at or towards the end of a course.
\end{abstract}

Objective: To determine the teachers' view about the influence of formative assessment on the result of summative assessment in undergraduate medical course.

Method: This cross sectional descriptive study was carried out from July 2009 to June 2010 over 106 teachers of selected two government and two private medical colleges. A structured and pretested questionnaire included different opinion about the influence of formative assessment on summative assessment was distributed among respondents and data were collected for analysis.

Results: This study revealed that majority of the teachers (77\%) considered feedback from formative assessment to students is important to close up the learning gap. Eighty two percent teachers were in agreement that through formative assessment teachers identified students' weak point and $69 \%$ supported that formative assessment motivates the students for deep learning and regular study However, frequent formative assessment hampers students' independent learning which produces negative effects in summative exam.

Conclusion: Formative assessment has got significant effect on summative assessment in various aspects.

Key Words: Formative assessment, summative assessment, Teachers, Intern doctors.

\section{Introduction}

Over the past several decades, educational researcher is in agreement that one way to improve student success is to increase the frequency of examination. The use of assessment to provide feedback to teachers and students over the course of instruction is called formative assessment (Taradi, S.K, 2005). Black and William (1998) perceive feedback as central to formative assessment, defining it as: "Any information that is provided to the performer of any action about that performance". On the other hand summative assessment involves only marking and grades to students. Black \& William (1999) stated that "Summative assessment is that to sum up learning. It looks at post achievement only". As opposed to a summative assessment designed to make judgments about students' performance and produce grades, the role of a formative assessment is to

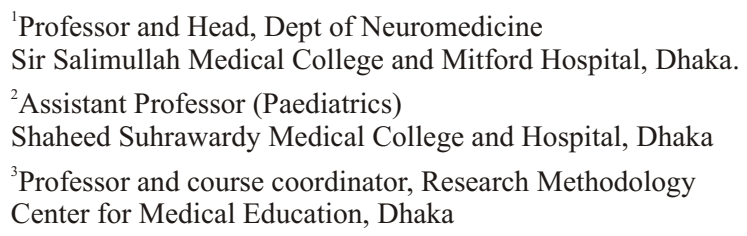

Contact Address: Prof. Sakhawat Hossain

Cell: 01711546736,E-mail: sakhawatdec@yahoo.com improve learning (Rushton, A, 2005). Cowic \& Bell (1999) defined formative assessment as the bidirectional process between teacher and students to enhance, recognize and respond to the learning. Nicole and Macfarlane-Dick (2006) have re-interpreted research on formative assessment and feedback and shown how these processes can help students control of their own learning (self-regulated learning). From the very beginning of Medical education of Bangladesh in course assessment items, card exam have been practicing in some disciplines in the medical colleges, which was inherited from ruler of British Empire thereafter Federal of Pakistan. During those periods the assessment system in medical education of the country was solely nonreferenced. To ensure quality products from medical colleges it is essential to have a complete, excellent teaching learning environment and valid assessment. An effective formative assessment can motivate the students for regular study and direct towards deep learning. It can also detect the student's learning gap whereby student can provide effort to close it up and teacher can supplement and modify the teaching session. Not only this, phobia for final exam is also ameliorated by repeated formative test. Keeping the above facts in mind the new undergraduate curriculum 2002 for medical education has been launched in MBBS curriculum in Bangladesh. It has specified the learning objective of each session and aimed of every subjects of MBBS course. It is

Bangladesh Journal of Medical Education 2012;3(1):18-21. C 2012 Hossain et al., publisher and licensee Association for Medical Education. This is an Open Access article which permits unrestricted non-commercial use, provided the original work is properly cited. 
high time to assess how much formative assessments can influence the performance in summative assessment, particularly in clinical subject. The aim of this study was to determine the teachers' view about the influence of formative assessment on the result of summative assessment in undergraduate medical course.

\section{Methodology}

This cross sectional type of descriptive study was carried out in 2 public medical colleges (Dhaka Medical College and Sir Salimullah Medical College) and 2 private medical colleges (Bangladesh Medical College and Holy Family Red Crescent Medical College) in Dhaka city from July 2009 to June 2010. A structured questionnaire reflecting the influence of formative assessment on summative assessment was prepared. Pre-testing was done on 10 teachers from Shaheed Suhrawardy Medical College. One hundred and six teachers working in the department of Medicine and Paediatrics of the selected medical colleges who were willing to fill-up the questionnaire were included in the study as respondents. Teachers who were not available and were not willing to take part in this research work were excluded from the study. Purpose of the study was duly explained to the respondent. Information and identity of the respondent were kept confidential. Written consents were sought duly from the authority. Completed data and questionnaire were collected, edited and processed and analyzed by using SPSS computer package.

\section{Results}

Among the respondent $79(19.5 \%)$ teachers were from government medical colleges and $27(6.7 \%)$ teachers were from non-government medical colleges. Among the responding teachers $26(25.52 \%)$ were professors who had mean teaching experience of 20.19 yrs. Seventeen were Associate professors having mean teaching experience of 15.41 years, 30(28.30\%) were Assistant Professor having mean teaching experience of 4.35 years and $33(31.13 \%)$ were Registrar having mean teaching experience of 27 years. Table 1 shows that $16(15 \%)$ teachers strongly agreed and $66(62.3 \%)$ agreed with the statement that learning gaps could be identified by formative assessment and thereby could be made up by further effort for summative assessment. On the other hand $9(8.5 \%)$ teachers disagreed and none of the teachers strongly disagreed in this point. Among the teachers 22(20.8\%) strongly agreed and $69(65.1 \%)$ teachers agreed that through formative assessment teachers identified student's weak point and thereby can plan to give appropriate feedback to student for further improvement in summative assessment (Table 2). Seventeen $(16 \%)$ teachers strongly agreed that formative assessment encourage students deep learning which improves the results in summative assessment' where as $56(52.8 \%)$ teachers agreed with the statement. On the other hand $9(8.5 \%)$ teachers disagreed and none of the teachers strongly disagreed in this point (Table 3). Regarding "formative assessment hampers student's independent learning which produces negative effect in the performance of Summative assessment' 7(6.6\%) and 50(47.2\%) of the teachers strongly agreed and agreed respectively in their opinion (Table 4). Most of the teachers wanted less than 20$30 \%$ marks of formative assessment to add in summative assessment (Figure 1).

Table 1: Distribution of respondents by their opinions about the statement that students identify their learning gaps by formative assessment and thereby try to close it by further effort for summative assessment

\begin{tabular}{lcc}
\hline Different level of opinion & \multicolumn{2}{c}{ Teacher } \\
& Frequency & $\%$ \\
\hline Strongly Disagree & 0 & $0 \%$ \\
Disagree & 9 & $8.5 \%$ \\
Neither agree nor disagree & 15 & $14.2 \%$ \\
Agree & 66 & $62.3 \%$ \\
Strongly Agree & 16 & $15 \%$ \\
Total & 106 & $100 \%$ \\
\hline
\end{tabular}

Table 2: Distribution of the respondents by their opinion about the statement that through formative assessment teachers identified student's weak point and thereby can plan to give appropriate feedback to student for further improvement in summative assessment

\begin{tabular}{lcc}
\hline Different level of opinion & \multicolumn{2}{c}{ Teacher } \\
& Frequency & $\%$ \\
\hline Strongly Disagree & 0 & $0 \%$ \\
Disagree & 7 & $6.6 \%$ \\
Neither agree nor disagree & 8 & $7.5 \%$ \\
Agree & 69 & $65.1 \%$ \\
Strongly Agree & 22 & $20.8 \%$ \\
Total & 106 & $100 \%$ \\
\hline
\end{tabular}

Table 3: Distribution of the respondents by their opinion about the statement that formative assessment encourages the students for deep learning which improves the results in summative assessment

\begin{tabular}{lcc}
\hline Different level of opinion & \multicolumn{2}{c}{ Teacher } \\
& Frequency & $\%$ \\
\hline Strongly Disagree & 0 & $0 \%$ \\
Disagree & 9 & $8.5 \%$ \\
Neither agree nor disagree & 24 & $22.7 \%$ \\
Agree & 56 & $52.8 \%$ \\
Strongly Agree & 17 & $16 \%$ \\
Total & 106 & $100 \%$ \\
\hline
\end{tabular}

Bangladesh Journal of Medical Education 2012;3(1):18-21. 
Table 4: Distribution of the respondents by their opinion about the statement that frequent formative assessment hampers student's independent learning which produces negative effect in the performance of summative assessment

\begin{tabular}{lcc}
\hline Different level of opinion & \multicolumn{2}{c}{ Teacher } \\
& Frequency & \% \\
\hline Strongly Disagree & 4 & $3.8 \%$ \\
Disagree & 23 & $21.7 \%$ \\
Neither agree nor disagree & 22 & $20.7 \%$ \\
Agree & 50 & $47.2 \%$ \\
Strongly Agree & 7 & $6.6 \%$ \\
Total & 106 & $100 \%$ \\
\hline
\end{tabular}

Figure 1: Teachers' view about the statement that what percentage of marks of formative assessment should be added with summative assessment

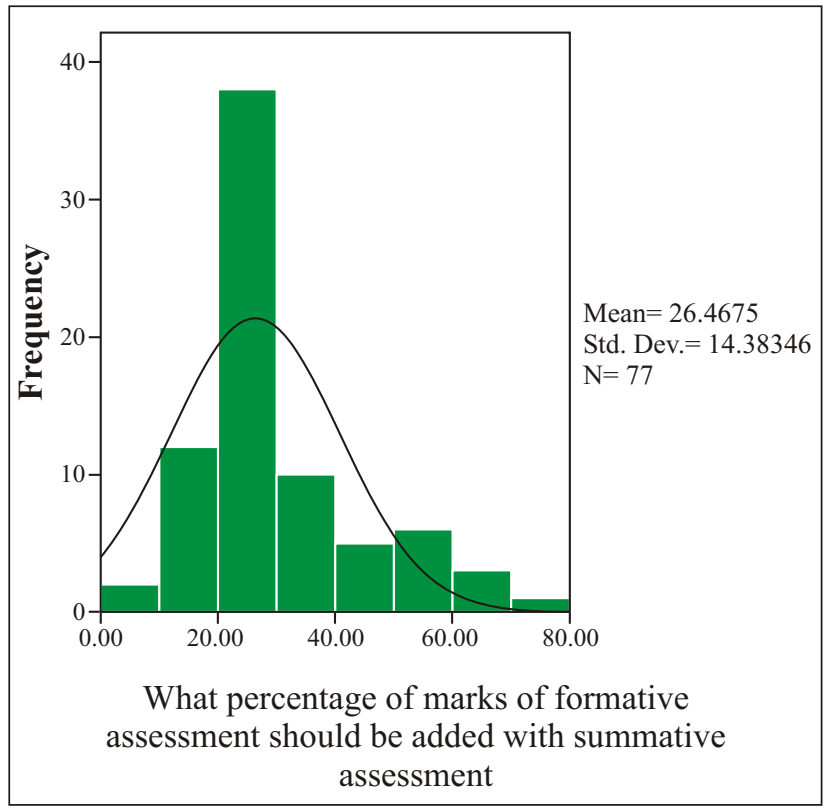

\section{Discussion}

To ensure quality products from medical colleges it is essential to have a complete, excellent teaching learning environment and valid assessment. Majority of the teachers that is $77.3 \%$ (strongly agreed $15.1 \%$ and agreed $62.3 \%$ ) considered that students identify their learning gaps by formative assessment. Futak (1996) have mentioned according to National Research Council (1999) of Washington D.C there are three central questions for the students or teachers in formative assessment. These are: 1) where are you going? 2) Where are you now? 3) How are going to get there? This three step process is called the "feedback loop" in the formative assessment; that is 1) setting a learning goal 2) determining the gap between the learning goal and the student's present state of understanding and 3) formulating feedback to close the gap. Sadler (1989) described the process of goal setting in detail. When goals are specific rather than vague have been shown to be most effective at capturing students' attention and increasing mobilization on a task. According to (Sadler 1989; Black \&William 1998) Futak (2000) suggested to inform the students about the gap, the teacher can include eliciting students' thinking through the verbal or written prompts, reviewing students' notebook or homework, or listening to small group conversations, so that students can compare their level of performance with goal. Black and William (1998) mentioned that the most important issues of all kinds of formative assessment are using that information of teaching, learning and thus closing the gap. Majority of the teachers $(82 \%)$ opined that through formative assessment teachers identified students' weak point and thereby can plan to give appropriate feedback to student for further improvement in summative assessment. A study was conducted by Vag \& Avadhhany (1996) at St. Johnson's Medical College, Bangalore, India to find out areas required revision after lecturing on the core areas of Physiology after administering formative exercise. The finding indicated that formative assessment can be an important tool for teachers and students for their academic activity. It helps to identify the areas of their strength and weakness without incurring any academic penalty. It also allow for rapid remedial action. It provides important feedback to the teacher to evaluate the efficacy of their lecture and to identify the areas which need re-emphasis or require an alternative strategy. Sadler (1989) has mentioned 'Teachers use feedback to make programmatic decisions with respect to readiness, diagnosis and remediation. Students use it to monitor the strength and weakness of their performances, so that aspects associated with success or high quality can be recognized and reinforced and unsatisfactory aspects modified or improved.' Similarly from Black and William (1998) mentioned 'For assessment of function formatively, the results have to be used to adjust teaching and learning. Feedback to any pupil should be about the particular qualities of his or her work, with advice on what he or she can do to improve and should avoid comparisons with other pupils'. Sixty nine percent of the teachers (strongly agreed $16 \%$ and agreed 52.8\%) supported formative assessment to encourage the students for deep learning. Black and William (1998) also showed that deep approach of learning is also encouraged by formative assessment. A good number of teachers (54\%) opined that too frequent formative assessment hampers student's independent learning which produces negative effect in the performance of summative assessment. Results of this study are suggestive of that too frequent formative assessment is harmful rather than beneficial for the students.

\section{Conclusion}

This study was designed to explore teachers' evaluation about the influence of formative assessment on summative assessment in undergraduate course. The study revealed that formative assessment has got significant effect on summative assessment in various aspects. Feedback from formative assessment to both students and teachers plays an

Bangladesh Journal of Medical Education 2012;3(1):18-21. 
important role in teaching-learning processes. Formative assessments also motivate the students for regular study and encourage them for deep learning. Too frequent formative assessment, however, hampers students' independent learning which produces negative effect on summative exam.

\section{References}

Black, P \& William D, 1998, 'Assessment and Classroom learning', Assessment in Education, vol. 5, pp. 7-75.

Black, P \& William, D 1999, 'Assessment and Classroom learning', Assessment in Education, vol. 5, pp. 103-110.

Cowie, B \& Bell, B 1999, 'A model of formative assessment in science education', Assessment in Education, vol. 6, pp. 101-116.

Furtak, EM 2000, Formative assessment in K-8 Science education: A conceptual review, school of education, Standard University, Viewed 8 February 2008, www 7. national a c a d e mies.org/bos e / 1 science_learning_commissioned_papers.html.
National research council for fair and open testing 1999, the value of formative assessment. Fair Test Examiner, Retrieved October 29, 2001, from http// www. Fairtest.org.examarts/winter99/k-forma3.html.

Nicole, DJ \& Mackferlane, D 2006, 'Formative assessment and self regulated learning: A model and seven principles of good feedback practice,' Studies in higher education, vol. 31, no.2, pp. 199-216.

Rushton, A 2005, 'Formative assessment: A key to deep learning?', Medical Teacher, vol. 27, no. 6, pp. 509-13.

Sadler, DR 1998, 'Formative assessment: revisiting the territory', Assessment in Education, vol 1, pp. 77-84.

Taradi, SK, Taradi, M \& Radic, K 2005, 'Integration of online formative assessment into medical education: Experience from University of Zagreb Medical School, Croatia', The National Medical Journal of India, vol. 18. no. 1, pp. 39-40.

Vag, M, Avadhhany, ST \& Rao, BS 1996, 'perspective on the role of formative assessment in physiology', Medical Teacher, vol. 18, no.4, pp.324 - 6 . 